Editorial review: This article has been subject to an editorial review process.

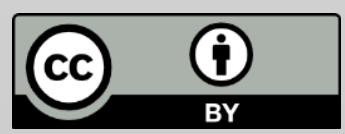

Copyright notice: This article is issued under the terms of the Creative Commons Attribution License, which permits use and redistribution of the work provided that the original author and source are credited.

You must give appropriate credit (author attribution), provide a link to the license, and indicate if changes were made. You may do so in any reasonable manner, but not in any way that suggests the licensor endorses you or your use. You may not apply legal terms or technological measures that legally restrict others from doing anything the license permits.

https://creativecommons .org/licenses/by/4.0/

\section{Do Legitimate Publishers Benefit or Profit from Error, Misconduct or Fraud?}

\author{
Jaime A. Teixeira da Silva ${ }^{1}$, Quan-Hoang Vuong ${ }^{2,3}$ \\ ${ }^{1}$ Independent researcher, Ikenobe 3011-2, P. O. Box 7, Miki-cho, Kagawa-ken \\ 761-0799, Japan \\ ${ }^{2}$ Centre for Interdisciplinary Social Research, Phenikaa University, Ha Dong \\ District, Hanoi 100803, Viet Nam \\ ${ }^{3}$ Centre Emile Bernheim, Université Libre de Bruxelles, 1050 Brussels, Belgium \\ Correspondence: jaimetex@yahoo.com, hoang.vuongquan@phenikka-uni.edu
}

\section{Abstract}

One of the aspects of post-publication peer review that is difficult for reputable journals or publishers to accept is that it may reveal flaws in their oft-claimed resilient peer review and efficient editorial management. Prospective authors are frequently sold a brand-associated image of a failsafe process, rigorous editorial handling, and stringent peer review. Yet, in reality, a sector of the published literature that has passed through claimed rigorous screening may still be flawed and contain errors, while some of the peer-reviewed literature is the product of fraud or misconduct. Even top-ranked journals, in terms of journal-based metrics such as the Clarivate Analytics' journal impact factor, or those that are indexed or hosted on platforms like PubMed, Scopus or Web of Science, have published papers with associated errata or retractions. In such journals, it is possible that erroneous literature has yet to be detected. This paper argues that publishers draw benefit in the form of metrics-based recognition, such as citations to erroneous or retracted papers, or financial reward, either as subscription fees or in the form of article processing charges, neither of which is refunded when a peer-reviewed academic paper is retracted. Knowing that peer review and editorial decisions can be imperfect, publishers have a moral responsibility of toning down claims of the excellence or perfection of peer review when advertising their journals, or they should conduct a full-scale post-publication peer review of their journals' entire collection to prove it. In turn, academics need to be more proactive in the publishing ecosystem, seeking to correct the literature when errors are found, and not be afraid to call out editors or publishers that defy their claimed academic or ethical excellence.

Keywords: article processing charge; APC; confidentiality; funding; instructions for authors; library; open access; post-publication peer review; predatory publishing 


\section{Introduction}

In June 2020, two prestigious medical journals, The Lancet and The New England Journal of Medicine (NEJM), decided to retract two major papers related to the treatment of COVID-19 upon detection of fraudulent data (Piller \& Servick, 2020). That case brought greater attention to the fact that flawed research could pass, and did pass, through the claimed rigorous screening of even the most reputable journals. The implication is alarming: there exists inaccurate and/or fabricated research in the scientific literature that is yet to be detected and retracted, even among the most highy ranked journals. As scientific output increases across disciplines, the number of retracted articles is also rising, threatening the health of the scientific enterprise (Hesselmann et al., 2017; Vuong, 2020). Setting flawed but as yet undetected papers aside, it takes an average of three years to retract an inaccurate or fraudulent paper (Abritis, Marcus, \& Oransky, 2021). The presence of low-quality scientific articles in the literature is compounded by continued citations, even post-retraction citations, to articles that were already withdrawn (Bar-llan \& Halevi, 2017). There are multiple reasons why retracted papers continue to be cited, and citations to such literature may either be critical or supportive (Teixeira da Silva, 2020a).

What is little discussed is how, even in the cases of retractions for academic misconduct, publishers and journals continue to draw benefits, whether in the form of citations to erroneous/retracted papers, the nonrefundable article processing charges (APCs), or journal subscription fees. For academic publishing to rid itself of unethical practices and outcomes, it is thus important to re-examine the nature of academic fraud and the responsibilities of those involved, especially researchers, editors, and publishers.

\section{Academic Fraud is Multi-Faceted}

A recent paper by Wilson (2020) published in Exchanges assumes a critical stance with regards to the issue of academic fraud, emphasizing how it can threaten academic integrity and thus, by association, impact society. Wilson offered an overview of the forms of academic fraud and misconduct, broadly characterizing them as being (1) internal, i.e., researcher-driven, either through fabrication, falsification, or plagiarism, or (2) external, i.e., publisher- or organization-driven through predatory practices, hoaxes and forgeries. The binary categorization by Wilson falls short of capturing the complicated procedures underlying many cases of academic misconduct. In reality, unethical behaviours in research are rarely limited to mere researchers or publishers but can also be found among editors and peer reviewers. 
First, while there are researchers who are overly ambitious and have committed academic dishonesty, the matter is not exclusively researcherdriven. Peer reviewers or editors may abuse their position, for example, requesting authors to cite their work or journal in a bid to boost their metrics, even if such actions are inappropriate (Teixeira da Silva, 2017). Indeed, reviewer misconduct is far from rare, but this issue is frequentlyor perhaps conveniently, given how reliant the publishing industry is on them - overlooked. Many studies have surveyed and documented the phenomenon of authors being asked or encouraged to revise their papers, including rounding off a $p$-value, selectively reporting a hypothesis, excluding certain findings, and even modifying the results against the authors' better judgment (Bergh, Sharp, Aguinis, \& Li, 2017; Frey, 2003; Shibayama \& Baba, 2015). Researchers, fuelled by increased competition for grant funding, tenure position, and promotion at work, are under pressure to comply with referees' requests so that their revised manuscripts are able to pass another round of screening. What is clear is that not all cases of academic dishonesty, especially when fabrication happens, lead to retractions.

On the contrary, dishonest conformity in peer review has often gone undetected, giving the publication of an article the appearance of business as usual (Shibayama \& Baba, 2015). Similarly, under-discussed is editorial misconduct, which differs case by case but generally includes negligent peer review, lack of guidelines for authors, publications of articles outside the journal's scope and mission, deliberate omission of conflicts of interest (Teixeira da Silva, Dobránszki, Bhar, \& Mehlman, 2019; Teixeira da Silva, 2021a), abuses of advertisements, and incomplete or disingenuous retraction notices (Shelomi, 2014). Journal editors are often hesitant in responding to a retraction request because of the amount of work that would involve, such as launching an investigation to confirm the errors or misconduct in the requested paper (Vuong, 2020). Moreover, they and their journal would be directly implicated in quality oversight during peer review, so there is an active lack of incentives to correct the literature. These behaviours are not necessarily predatory in nature and may easily escape scrutiny due to the lack of independent oversight.

Second, hoaxes and forgeries, including sting operations, are not exclusively driven by publishers or organizations and can be driven by individuals who establish fake identities. One of the well-known sting operations was carried out by John Bohannon, who used a number of fake names to submit different versions of a fabricated 'scientific' paper to hundreds of open access (OA) journals, finding that many - including legitimate, peer-reviewed and indexed journals - were willing to accept the paper (Bohannon, 2013). However, using dishonest and/or fraudulent practices to detect dishonesty and/or fraud is itself a dishonest and/or 
fraudulent tactic, not to mention unscholarly and unethical, so there are no deontological, moral or ethical arguments to offer support for the use of such operations in academic publishing (Teixeira da Silva, 2021b).

Wilson (2020) provides a wider and more in-depth discussion about the issue of fraud in academic publishing.

\section{Academic Publishing is More Than a Binary Classification}

To submit a manuscript to an academic or scholarly journal, authors have to follow established ethical guidelines and offer assurances such as data originality, non-duplicate submission, and a host of other requests and ethical guarantees. The demanding and stringent submission requirements understandably serve to ensure the scientific and ethical quality of a manuscript, but they are making academic publishing increasingly challenging and strenuous (Teixeira da Silva, 2016). The timeconsuming nature of the publishing process entails an unavoidable delay in the dissemination of scientific findings. Thus, the current academic publishing model is frequently criticized for being outdated, slow, costly, and counterproductive for science (Stern \& O'Shea, 2019; Vuong, 2018). However, an inefficient journal, even with incompetent editors, is not necessarily a predatory or unscholarly one, although many scholars may be easily tempted to confound these categories of journals.

In his article, Wilson (2020) alluded briefly to the exploitative nature of predatory entities. Still, he did not indicate that a priori, it might be difficult to differentiate the predatory nature of a journal simply from its submission or ethical requirements. Moreover, except for extreme cases, there is no crisp distinction between legitimate and predatory entities, and a wide zone of grey quality, predation, and exploitation exists (Teixeira da Silva, 2020b). It seems insufficient to merely classifying journals into a binary choice (either predatory or not), for the act by default equates poor quality with misconduct, but that is not necessarily the case (Eriksson \& Helgesson, 2018). Consequently, stated ethical requirements by a journal, legitimate or predatory, are not in themselves a guarantee that peer review or editorial handling will be valid, resulting in error-free publication, or suffice to detect fraudulent aspects. 


\section{In the Pursuit of Indexing, Ranking, Branding, and Profitability}

The business of academic publishing retains many practices that, for a large part, serve the publishers and journals themselves. This section casts doubt on a number of these practices by taking into account both the conventional publishing model as well as recent changes, such as the emergence of $O A$ journals and the post-publication peer-review process.

\section{Conventional Publishing Practices}

In the world of commercial academic publishing, it is not just the expectation that journals be indexed and ranked by certain measures and in certain platforms; it is also the norm. Journals, especially those that unverifiable claim to be peer-reviewed and carry a prestige-associated journal-based metric such as a Clarivate Analytics' journal impact factor (JIF), often use these aspects to 'sell' their image. The overemphasis on such branding creates the sometimes false or misleading impression that submission to such journal(s), although not a guarantee of publication, would guarantee, if accepted, rigorous peer review-based quality control, editorial scrutiny, and thus a 'safe' (i.e., that has undergone strict quality control) paper. Branding does not end there. Sadly, far too many academics are caught up in the glamor and vanity world of journal indexes and ranking, striving to be seen and read in higher-ranked journals, failing to appreciate or perhaps intentionally ignoring the marketing gimmicks that underlie many aspects of the for-profit academic publishing industry. Gamed metrics carry no academic, scholarly or educational value (Oravec, 2020).

With the common denominator being Clarivate Analytics, journals with a JIF are essential to the Web of Science, which is considered one of the three most popular and/or reputable indexes or platforms, alongside Elsevier's Scopus and NCBI's PubMed. To be indexed in such databases carries an added image of 'prestige'. In many (if not most) of these cases, the journals would advertise their compliance to strict ethical rules, such as those by the Committee on Publication Ethics (COPE), in the form of ethics branding. As one example, Chambers, Michener, and Falcone (2019) noted that of the 176 PubMed-indexed retractions of papers in the obstetrics and gynecology literature, plagiarism and data falsification accounted for almost $45 \%$ of the total. Campos-Varela et al. (2020) indicated that retractions were made from over 600 PubMed-indexed journals, suggesting that there are integrity problems not only with journals indexed in PubMed but with PubMed management itself (Teixeira da Silva, 2021c). Despite this, those journals continue to be indexed in PubMed, and those that carry a JIF continue to benefit from this metric despite these cases of academic misconduct. Here, journals and publishers 
that publish erroneous or even fraudulent research continue to derive 'benefit' in the form of sustained indexing and unaltered metrics.

The financial or reputation rewards are not limited to editors but may also be bestowed on peer reviewers, who may receive an APC discount voucher for submission to a journal of the same publisher (Epstein, Wiseman, Salaria, \& Mounier-Jack, 2017) or be recognized on peer rewards platforms such as Publons (Van Noorden, 2014; Teixeira da Silva \& Katavić, 2016). While there are legitimate reviewers who give genuine feedback and help the authors improve their manuscripts, there are also reviewers with questionable profiles and incentives. In such cases, should recognition be conferred to those whose peer reports cannot be openly and independently scrutinized? Should reviewers who have peer-reviewed papers in predatory journals merit praise or those that approved erroneous work for a publication that is later retracted due to misconduct or fabrication - undetected by peers and editors - deserve peer review credits, such as on Publons (Teixeira da Silva, 2020c)?

Based on these 'quality'-based guarantees, publishers or stand-alone journals then sell their 'product', a claimed peer-reviewed journal, to clients, such as institutional libraries. Journal subscriptions are either single stand-alone journal annual or multi-year subscriptions, or packages or 'bundles', i.e., access to print and/or online access to several journal titles (Bergstrom, Courant, McAfee, \& Williams, 2014). However, within 'bundles', there may be journals with flawed academic content mixed with strictly validated content. In such cases, is the knowledgeable sale of erroneous literature taking place? Considering that library funds generally cover such costs (Willinsky \& Rusk, 2019), the role of librarians, or other staff tasked with the purchase of academic journals, faces further scrutiny. One may ask whether it is the responsibility of librarians to carefully screen the academic legitimacy of journals (or their content) within subscriptions before they use university funds, sometimes very sizeable, to purchase journals. Suppose librarians are responsible for such a task. Are they required to possess a certain level of academic literacy (Braddlee \& VanScoy, 2019) because they are entrusted with using private or public funding to purchase literature that may be predatory, erroneous or the product of misconduct? More importantly, how should universities assess the quality or veracity of knowledge before a financial investment such as the costly years-long journal subscription?

\section{Emerging Publishing Practices}

In the evolving OA publishing market, revenue, especially for global market leaders, is drawn from APCs. Select publishers are making billions of US dollars in annual profit (Johnson, Watkinson, \& Mabe, 2018; Larivière, Haustein, \& Mongeon, 2015), with APCs averaging thousands of US\$ (Asai, 
2020). Whereas low APCs are not necessarily related to predatory publishing, high APCs may, to a certain extent, reflect financially exploitative publishing (Teixeira da Silva, Dobránszki, Tsigaris, \& AlKhatib, 2019). The survival of OA publishing, especially of for-profit publishers, hinges increasingly on journal APCs (Budzinski, Grebel, Wolling, \& Zhang, 2020; Morrison, 2018; Piwowar et al., 2018). In his analysis, Wilson (2020) drew readers' attention to the issue of predatory OA publishing but seemed to be oblivious to the fact that predatory behaviour is not restricted exclusively to OA journals or publishers. As discussed above, journal blacklists are deeply flawed because it is becoming increasingly difficult to distinguish between predatory and nonpredatory journals.

In post-publication peer review (PPPR), scrutiny of peer-reviewed papers may reveal that peer review has failed to some extent (Shashok \& Matarese, 2018; Teixeira da Silva, 2017; Teixeira da Silva \& Dobránszki, 2014; Tennant, 2018). Despite this, publishers continue to make sales from flawed research, containing either errors, misconduct, or fraud. Even though such studies are being retracted (Brainard \& You, 2018), which so far have accounted for less than $1 \%$ of the total literature published, publishers continue to sell subscriptions to journals with tainted content, including some indexed on PubMed (Teixeira da Silva, 2021c). Refunds are not paid to subscribers, nor are APCs refunded to authors or funders. Is there an ethical component to financial reward (sales or profit) made from the sale of flawed brands or products, even if that quality is not known, $a$ priori to PPPR? This issue needs to be discussed by COPE since papers in journals published by many COPE members are being retracted. That conversation also needs to encompass some of the main players in literary content databases, such as Clarivate Analytics' Web of Science, Elsevier's Scopus, and NCBI's PubMed, since these platforms also benefit reputationally from the inclusion of literature that might not be properly academically scrutinized, a topic of future expansion. Sales of, or profit from, research that is erroneous or fraudulent may further undermine the credibility of COPE (Teixeira da Silva, 2019), the public trust (Vuong, 2018), and the 'brand' value of its members.

\section{What Measures Should be Put in Place Going Forward?}

In cases where a flawed scholarly product is sold, what consequences should there be to editors who were rewarded, but who failed - to some extent - their mission to ensure the publisher's guarantees of peerreviewed academic scrutiny and quality (Resnik \& Elmore, 2016; Teixeira da Silva \& Dobránszki, 2018)? An answer likely lies in the level of error and in the spirit of transparency (Tennant, 2018) with which corrections are made. Consequently, editors who oversee content through PPPR, shown 
to be highly flawed, should be removed from their positions, as they may be perceived, like the quality control of the literature they oversaw, to be unreliable. Such removals could reinstate trust. By contrast, editors who have, in response to PPPR, used transparent measures to correct flawed literature deserve praise, thereby avoiding negative branding and stigmatization associated with retractions (Teixeira da Silva \& Al-Khatib, 2021), and to clearly distinguish valid, honest and trustworthy peer reviewers and editors from predatory ones. Addressing the responsibilities of peer reviewers who have overseen the quality of erroneous, flawed and/or fraudulent work is more difficult. While it is clear that unreliable and/or predatory peers should be banned or blacklisted from serving the academic community, the question remains as to how to implement this when the peer-review process takes place largely behind closed doors.

The questions of journal and publisher responsibilities loom larger when we consider their financial gains in the face of, and even despite, flawed or irreproducible research articles (França \& Monserrat, 2019). loannidis (2005) previously ran simulations on research designs and settings and found that the likelihood of a research claim being false is higher than true. If this theoretical postulation is considered true, then is a portion of the annual multi-billion-dollar profits of the global publishing market being derived from the sale of flawed research, i.e., research tainted with error, misconduct or fraud? To derive income, sales and/or profit or reputational benefits from flawed products defend the trade of those products is unethical. Yet, this mode of commercial academic publishing remains impenetrable. To accommodate this under-discussed ethical vs. capitalistic component (Khoo, 2019), many practices would need to evolve, one of which includes requiring the APC market to improve transparency, equality, and accessibility (Teixeira da Silva, 2020d).

In short, it is not exclusively illegitimate (i.e., 'predatory') journals or publishers that may display unscholarly publishing practices. As this paper has argued, unscholarly or unethical practices such as earning reputational and/or financial benefits from erroneous or fraudulent scientific work can be found in even legitimate journals and publishers. These include journals and publishers indexed in PubMed, Scopus, or Web of Science, which have more than 12,000 erroneous medical papers (Atanasov et al., 2020) and carry a branded metric like the JIF. Even those that claim to follow strict ethical (e.g., COPE) guidelines and rigorous peer reviews may also be drawing benefits from the system as a whole.

How can the benefit, actual or perceived, of publishers be moderated or proportionally reduced? This would likely involve multiple complex approaches, such as recognizing peer review as imperfect, fortifying transparency and heightening community engagement in PPPR (Tennant, 
2018). The metrics (e.g., JIF) of journals whose retracted literature is cited need to be corrected or adjusted downwards (Dobránszki \& Teixeira da Silva, 2019). Finally, researchers should take a more active stance in the publishing ecosystem (Vuong, 2020). Upholding academic integrity involves doing hard work, i.e., acknowledging one's shortcomings and errors, correcting the literature when errors are found, and calling out editors or publishers that defy their claimed academic or ethical excellence.

Jaime A. Teixeira da Silva is a botanist and molecular biologist by training, but with broader experience in plant breeding, horticulture, agronomy, and forestry, soil and environmental sciences. A keen interest in issues related to academic publishing, he has worked as an independent researcher over the past decade.

Quan-Hoang Vuong is the Founding Director of the Centre for Interdisciplinary Social Research, Phenikaa University in Hanoi, Vietnam. He is chairman of the Vietnam chapter of the European Association of Science Editors and serves in the NAFOSTED Scientific Council on Basic Research (Economics, 2019 to date). He has published academic papers and books with such publishers as BMC, Brill, Elsevier, Emerald, De Gruyter, Dove, Inderscience, MIT Press, Nature Publishing Group, Oxford University Press, Palgrave Macmillan, Praeger, Springer, Taylor \& Francis, Wiley, World Scientific, etc.

\section{References}

Abritis, A., Marcus, A., Oransky, I. (2021). An "alarming" and "exceptionally high" rate of COVID-19 retractions? Accountability in Research 28(1): 58-59. https://doi.org/10.1080/08989621.2020.1793675 [Accessed: 23 January 2021].

Asai, S. (2020). Market power of publishers in setting article processing charges for open access journals. Scientometrics 123(2): 1037-1049.

https://doi.org/10.1007/s11192-020-03402-y [Accessed: 23 January 2021].

Atanasov, A.G., Yeung, A.W.K., Klager, E., Eibensteiner, F., Schaden, E., KleteckaPulker, M., Willschke, H. (2020). First, do no harm (gone wrong): total-scale analysis of medical errors scientific literature. Frontiers in Public Health 8 , 558913. https://doi.org/10.3389/fpubh.2020.558913 [Accessed: 23 January 2021].

Bar-llan, J., Halevi, G. (2017). Post retraction citations in context: a case study. Scientometrics 113(1): 547-565. https://doi.org/10.1007/s11192-017-2242-0 [Accessed: 23 January 2021]. 
Bergh, D.D., Sharp, B.M., Aguinis, H., Li, M. (2017). Is there a credibility crisis in strategic management research? Evidence on the reproducibility of study findings. Strategic Organization 15(3): 423-436. https://doi.org/10.1177/1476127017701076 [Accessed: 23 January 2021].

Bergstrom, T.C., Courant, P.N., McAfee, R.P., Williams, M.A. (2014). Evaluating big deal journal bundles. Proceedings of the National Academy of Sciences USA 111(26): 9425-9430. https://doi.org/10.1073/pnas.1403006111 [Accessed: 23 January 2021].

Bohannon, J. (2013). Who's afraid of peer review? Science 342(6154): 60-65. https://doi.org/10.1126/science.342.6154.60 [Accessed: 23 January 2021].

Braddlee, VanScoy, A. (2019). Bridging the chasm: Faculty support roles for academic librarians in the adoption of open educational resources. College \& Research Libraries 80(4), 426-449. https://doi.org/10.5860/crl.80.4.426 [Accessed: 23 January 2021].

Brainard, J., You, J. (2018). What a massive database of retracted papers reveals about science publishing's 'death penalty'. Science 25(1), 1-5.

https://doi.org/10.1126/science.aav8384 [Accessed: 23 January 2021].

Budzinski, O., Grebel, T., Wolling, J., Zhang, X. (2020). Drivers of article processing charges in open access. Scientometrics 124(3), 2185-2206. https://doi.org/10.1007/s11192-020-03578-3 [Accessed: 23 January 2021].

Campos-Varela, I., Villaverde-Castañeda, R., Ruano-Raviña, A. (2020). Retraction of publications: a study of biomedical journals retracting publications based on impact factor and journal category. Gaceta Sanitaria, 34(5), 430-434. https://doi.org/10.1016/i.gaceta.2019.05.008 [Accessed: 23 January 2021].

Chambers, L.M., Michener, C.M., Falcone, T. (2019). Plagiarism and data falsification are the most common reasons for retracted publications in obstetrics and gynaecology. BJOG 126(9), 1134-1140.

https://doi.org/10.1111/1471-0528.15689 [Accessed: 23 January 2021].

Dobránszki, J., Teixeira da Silva, J.A. (2019). Corrective factors for author- and journal-based metrics impacted by citations to accommodate for retractions. Scientometrics 121(1), 387-398. https://doi.org/10.1007/s11192-019-03190-0 [Accessed: 23 January 2021].

Epstein, D., Wiseman, V., Salaria, N., Mounier-Jack, S. (2017). The need for speed: the peer-review process and what are we doing about it? Health Policy and Planning 32(10), 1345-1346. https://doi.org/10.1093/heapol/czx129 [Accessed: 23 January 2021].

Eriksson, S., Helgesson, G. (2018). Time to stop talking about 'predatory journals'. Learned Publishing 31(2), 181-183. https://doi.org/10.1002/leap.1135 [Accessed: 23 January 2021]. 
França, T.F.A., Monserrat, A.M. (2019). Reproducibility crisis, the scientific method, and the quality of published studies: Untangling the knot. Learned Publishing 32(4), 181-183. https://doi.org/10.1002/leap.1250 [Accessed: 23 January 2021].

Frey, B.S. (2003). Publishing as prostitution? - Choosing between one's own ideas and academic success. Public Choice 116(1), 205-223.

https://doi.org/10.1023/A:1024208701874 [Accessed: 23 January 2021].

Hesselmann, F., Graf, V., Schmidt, M., Reinhart, M. (2017). The visibility of scientific misconduct: A review of the literature on retracted journal articles. Current Sociology, 65(6), 814-845. https://doi.org/10.1177/0011392116663807 [Accessed: 23 January 2021].

Ioannidis, J.P.A. (2005). Why most published research findings are false. PLOS Medicine 2(8), e124. https://doi.org/10.1371/journal.pmed.0020124 [Accessed: 23 January 2021].

Johnson, R., Watkinson, A., Mabe, M. (2018). The STM Report: An overview of scientific and scholarly publishing, October, 5 th edition, by the International Association of Scientific, Technical and Medical Publishers, The Hague, The Netherlands, 213 pp. https://www.stmassoc.org/2018 1004 STM Report 2018.pdf [Accessed: 29 March 2021].

Khoo, ST-S. (2019). Article processing charge hyperinflation and price insensitivity: An open access sequel to the serials crisis. Liber Quarterly 29(1), 118. https://doi.org/10.18352/lq.10280 [Accessed: 23 January 2021].

Larivière, V., Haustein, S., Mongeon, P. (2015). The oligopoly of academic publishers in the digital era. PLOS ONE 10(6), e0127502.

https://doi.org/10.1371/journal.pone.0127502 [Accessed: 23 January 2021].

Morrison, H. (2018). Global OA APCs (APC) 2010-2017: Major trends. ELPUB 2018, 10.4000/proceedings.elpub.2018.16, Toronto, Canada. Available at: https://elpub.episciences.org/4604/pdf [Accessed: 29 March 2021].

Oravec, J.A. (2020). Academic metrics and the community engagement of tertiary education institutions: emerging issues in gaming, manipulation, and trust. Tertiary Education and Management 26(1), 5-17.

https://doi.org/10.1007/s11233-019-09026-z [Accessed: 23 January 2021].

Piller, C., Servick, K. (2020). Two elite medical journals retract coronavirus papers over data integrity questions. Available at:

https://www.sciencemag.org/news/2020/06/two-elite-medical-journalsretract-coronavirus-papers-over-data-integrity-questions [Accessed: 29 March 2021].

Piwowar, H., Priem, J., Larivière, V., Alperin, J.P., Matthias, L., Norlander, B., Farley, A., West, J., Haustein, S. (2018). The state of OA: a large-scale analysis of the prevalence and impact of open access articles. PeerJ 6, e4375 https://doi.org/10.7717/peeri.4375 [Accessed: 23 January 2021]. 
Resnik, D.B., Elmore, S.A. (2016). Ensuring the quality, fairness, and integrity of journal peer review: A possible role of editors. Science and Engineering Ethics 22(1), 169-188. https://doi.org/10.1007/s11948-015-9625-5 [Accessed: 23 January 2021].

Shashok, K., Matarese, V. (2018). Post-publication peer review in biomedical journals: overcoming obstacles and disincentives to knowledge sharing. Roars Transactions 6(1), 10125. http://doi.org/10.13130/2282-5398/10125 [Accessed: 23 January 2021].

Shelomi, M. (2014). Editorial misconduct-definition, cases, and causes. Publications 2(2), 51-60. https://doi.org/10.3390/publications2020051 [Accessed: 23 January 2021].

Shibayama, S., Baba, Y. (2015). Dishonest conformity in peer review. Prometheus 33(3), 215-233. https://doi.org/10.1080/08109028.2015.1114745 [Accessed: 23 January 2021].

Stern, B.M., O'Shea, E.K. (2019). A proposal for the future of scientific publishing in the life sciences. PLOS Biology 17(2), e3000116.

https://doi.org/10.1371/journal.pbio.3000116 [Accessed: 23 January 2021].

Teixeira da Silva, J.A. (2016). The militarization of science, and subsequent criminalization of scientists. Journal of Interdisciplinary Medicine 1(2), 214-215. http://doi.org/10.1515/jim-2016-0031 [Accessed: 23 January 2021].

Teixeira da Silva, J.A. (2017). The ethics of peer and editorial requests for selfcitation of their work and journal. Medical Journal Armed Forces India 73(2), 181-183. http://doi.org/10.1016/i.mjafi.2016.11.008 [Accessed: 23 January 2021].

Teixeira da Silva, J.A. (2019). Debunking the loss of the Committee on Publication Ethics (COPE) moral compass: conspiracy theory, or genuine cause for concern? Eubios Journal of Asian and International Bioethics 29(3), 99-109. https://www.eubios.info/EJAIB52019.pdf [Accessed: 23 January 2021].

Teixeira da Silva, J.A. (2020a). Reasons for citing retracted literature are not straightforward, and solutions are complex. Journal of Applied Physiology 129(1), 3. doi: 10.1152/japplphysiol.00258.2020 [Accessed: 23 January 2021].

Teixeira da Silva, J.A. (2020b). Is there a clear division between predatory and low-quality journals and publishers? Journal of the Royal College of Physicians of Edinburgh 50(4), 458-459. http://doi.org/10.4997/JRCPE.2020.427 [Accessed: 23 January 2021].

Teixeira da Silva, J.A. (2020c). Are negative reviews, predatory reviewers or failed peer review rewarded at Publons? International Orthopaedics 44(10), 2193-2194. http://doi.org/10.1007/s00264-020-04587-w [Accessed: 23 January 2021]. 
Teixeira da Silva, J.A. (2020d). Three new suggested guidelines for increased transparency regarding open access article processing charges (APCS). Epistēmēs Metron Logos 4, 4-7.http://doi.org/10.12681/eml.24208 [Accessed: 23 January 2021].

Teixeira da Silva, J.A. (2021a). Conflicts of interest arising from simultaneous service by editors of competing journals or publishers. Publications 9(1), 6 . http://doi.org/10.3390/publications9010006 [Accessed: 23 January 2021].

Teixeira da Silva, J.A. (2021b). Assessing the ethics of stings, including from the prism of guidelines by ethics-promoting organizations (COPE, ICMJE, CSE). Publishing Research Quarterly, 37(1), 90-98. http://doi.org/10.1007/s12109021-09784-y [Accessed: 23 January 2021].

Teixeira da Silva, J.A. (2021c). Is the validity, credibility and reliability of literature indexed in PubMed at risk? Medical Journal Armed Forces India (accepted, DOI not yet assigned)

Teixeira da Silva, J.A., Al-Khatib, A. (2021) Ending the retraction stigma: encouraging the reporting of errors in the biomedical record. Research Ethics 17(2), (in press) http://doi.org/10.1177/1747016118802970 [Accessed: 23 January 2021].

Teixeira da Silva, J.A., Al-Khatib, A., Dobránszki, J. (2017). Fortifying the corrective nature of post-publication peer review: identifying weakness, use of journal clubs, and rewarding conscientious behavior. Science and Engineering Ethics 23(4), 1213-1226. http://doi.org/10.1007/s11948-016-9854-2 [Accessed: 23 January 2021].

Teixeira da Silva, J.A., Dobránszki, J. (2015). Problems with traditional science publishing and finding a wider niche for post-publication peer review.

Accountability in Research: Policies and Quality Assurance 22(1), 22-40.

http://doi.org/10.1080/08989621.2014.899909 [Accessed: 23 January 2021].

Teixeira da Silva, J.A., Dobránszki, J. (2018). Editors moving forward: stick to academic basics, maximize transparency and respect, and enforce the rules. Recenti Progressi in Medicina 109(5), 263-266.

http://doi.org/10.1701/2902.29244 [Accessed: 23 January 2021].

Teixeira da Silva, J.A., Dobránszki, J., Bhar, R.H., Mehlman, C.T. (2019) Editors should declare conflicts of interest. Journal of Bioethical Inquiry 16(2), 279-298. http://doi.org/10.1007/s11673-019-09908-2 [Accessed: 23 January 2021].

Teixeira da Silva, J.A., Dobránszki, J., Tsigaris, P., Al-Khatib, A. (2019). Predatory and exploitative behaviour in academic publishing: An assessment. The Journal of Academic Librarianship 45(6), 102071.

http://doi.org/10.1016/i.acalib.2019.102071 [Accessed: 23 January 2021].

Teixeira da Silva, J.A., Katavić, V. (2016) Free editors and peers: squeezing the lemon dry. Ethics \& Bioethics 6(3-4), 203-209. http://doi.org/10.1515/ebce2016-0011 [Accessed: 23 January 2021]. 
Tennant, J.P. (2018). The state of the art in peer review. FEMS Microbiology Letters 365(19), fny204. https://doi.org/10.1093/femsle/fny204 [Accessed: 23 January 2021].

Van Noorden, R. (2014). The scientists who get credit for peer review. Nature News. https://doi.org/10.1038/nature.2014.16102 [Accessed: 23 January 2021].

Vuong, Q.-H. (2018). The (ir)rational consideration of the cost of science in transition economies. Nature Human Behaviour 2(1), 5.

https://doi.org/10.1038/s41562-017-0281-4 [Accessed: 23 January 2021].

Vuong, Q.-H. (2020). Reform retractions to make them more transparent. Nature 582(7811), 149. https://doi.org/10.1038/d41586-020-01694-x

[Accessed: 23 January 2021].

Willinsky, J., Rusk, M. (2019). If research libraries and funders finance open access: moving beyond subscriptions and APCs. College \& Research Libraries 80(3), 340-355. https://doi.org/10.5860/crl.80.3.340 [Accessed: 23 January 2021].

Wilson, P.F. (2020). Academic fraud: solving the crisis in modern academia. Exchanges 7(3), 14-44. https://doi.org/10.31273/eiri.v7i3.546 [Accessed: 23 January 2021].

\section{To cite this article:}

Teixeira da Silva, J. A., \& Vuong, Q. H., 2021. Do Legitimate Publishers Benefit or Profit from Error, Misconduct or Fraud? Exchanges: The Interdisciplinary Research Journal, 8(3), 55-68. Retrieved from:

https://doi.org/10.31273/eirj.v8i3.785 